\title{
MODEL PEMBELAJARAN SISTEM BASIS DATA BERBASIS COMPUTER ASSISTED INSTRUCTION
}

\author{
Ruliah $^{1}$, Bahar $^{2 *}$, Andita Suci Pratiwi ${ }^{3}$
}

${ }^{1}$ Program Studi Sistem Informasi, STMIK Banjarbaru

2,3 Program Studi Teknik Informatika, STMIK Banjarbaru

${ }^{2}$ Program Pasca Sarjana Teknologi Pendidikan, Universitas Negeri Jakarta

1.

Email Corresponding Author: *bahararahman@gmail.com

\section{ABSTRACT}

The direct (face-to-face) learning approach that is centered on the teacher in Data Base System lectures causes the learning process to be passive. Students' understanding is not optimal in certain competencies so that the final average of students does not reach the predetermined competency standards. This paper presents a learning model for Computer Assisted Instruction (CAI) Database System with a combination of Tutorial and Drill and Practice models. The research uses the $R \& D$ (Research and Development) method with three main stages, namely conducting an initial study to find information about the learning model to be developed, developing a model based on the results of the problem study, and conducting field trials. The results of the pretest and posttest showed an increase in learning completeness by $72.41 \%$, as evidenced by the significance test which experienced a significant increase.

Keywords: Learning Model, Database System, Computer Assisted Instruction, Research and Development, Tutorial, Drill and Practice

\section{ABSTRAK}

Pendekatan pembelajaran langsung (tatap muka) yang berpusat pada pengajar dalam perkuliahan Sistem Basis Data menyebabkan proses belajar menjadi pasif. Pemahaman mahasiswa tidak maksimal pada bagian kompetensi tertentu sehingga rerata nilai akhir mahasiswa tidak mencapai standar kompetensi yang telah ditetapkan. Paper ini menyajikan model pembelajaran Sistem Basis Data berbantuan Komputer (Computer Assisted Instruction/ CAI) dengan kombinasi model Tutorial dan Drill and Practice. Penelitian menggunakan metode $R \& D$ (Research and Development) dengan Tiga tahapan utama, yaitu melakukan studi awal untuk mencari informasi mengenai model pembelajaran yang akan dikembangkan, mengembangkan model berdasarkan hasil kajian permasalahan, dan melakukan uji coba lapangan. Hasil uji pretest dan posttest menunjukkan adanya peningkatan ketuntasan belajar sebesar 72,41\%, yang dibuktikan dengan uji signifikasi yang memperlihatkan adanya peningkatan yang signifikan.

Kata Kunci: Model Pembelajaran, Sistem Basis Data, Computer Assisted Instruction, Research and Development, Tutorial, Drill and Practice

\section{PENDAHULUAN}

Basis Data adalah salah satu bidang ilmu yang memiliki peran penting dalam bidang Sistem Informasi dan Teknologi Informasi. Basis Data banyak digunakan dalam dunia desain berbantuan komputer, kecerdasan buatan, e-commerce, administrasi dan sains, dan berbagai bidang Teknologi Informasi lainnya
(Yuelan, Yiwei, Yuyan, \& Yuefan, 2011). Basis data menjadi bagian yang memiliki peran sangat strategis bagi Sistem Informasi untuk mendukung manajemen mengambil suatu keputusan (Mario dan Oscar, 2000). Sistem basis data menyediakan sarana akses yang fleksibel, memproteksi data dari kerusakan, dan menghindarkan penggunaan yang tidak legal. Sistem basis data menyediakan 
sarana untuk penggunaan secara bersama seperti: keterhubungan data untuk meminimalkan kerangkapan data, pemeliharaan integritas data, dan menghilangkan ketergantungan data pada program-program aplikasi. Sistem basis data juga menstandarkan definisi elemen data untuk dapat diakses oleh berbagai teknologi pemrosesan data dan penyajian informasi (Ramez dan Shamkant, 2016).

Kurikulum Sistem Basis Data pada Perguruan Tinggi Bidang Informatika di Indonesia pada umumnya masih menggunakan moda pendidikan tradisional berupa pembelajaran tatap muka (traditional face-to-face) dalam ruang kelas, yang menekankan pada sistem pembelajaran berpusat pada pengajar. Hasil studi pendahuluan pada penelitian ini menunjukkan bahwa metode pembelajaran langsung (tatap muka) yang berpusat pada pengajar untuk perkuliahan Sistem Basis Data menyebabkan proses belajar menjadi pasif. Pemahaman mahasiswa tidak maksimal pada bagian kompetensi tertentu sehingga nilai akhir mahasiswa masih banyak yang tidak mencapai standar kompetensi yang telah ditetapkan. Suasana belajar dalam ruang kelas juga menjadi membosankan. Beberapa mahasiswa terlihat memerlukan perhatian dan penanganan khusus pada saat belajar, namun tidak dapat ditangani oleh pengajar karena tidak tersedia waktu yang cukup untuk melakukan pendampingan langsung. Kondisi seperti dikemukakan diatas sejalan dengan penemuan Simarmata, Limbong, Napitupulu, Sriadhi, Tambunan, dan Sinaga (2018) yang mengemukakan bahwa guru menghadapi kesulitan menyampaikan seluruh materi pada model pembelajaran konvensional karena alokasi waktu yang terbatas, akibatnya siswa tertinggal mengikuti pembelajaran, dan menyebabkan siswa tidak dapat mencapai standar kompetensi minimum yang direncanakan dalam desain pembelajaran.

Pembelajaran berbantuan komputer (Computer Assisted Instruction/ CAI) merupakan pendekatan pembelajaran interaktif di mana komputer dapat menggantikan peran pengajar. Pembelajaran berbantuan komputer menyediakan instruction, tes, dan umpan balik belajar bagi peserta didik secara mandiri, dengan keterlibatan pengajar yang sangat sedikit atau tidak sama sekali (Darmawan, 2011). Dengan demikian, permasalahan keterbatasan waktu bagi pengajar untuk setiap saat mendampingi peserta didik dalam proses belajar diharapkan dapat teratasi.

Paper ini menyajikan model pembelajaran Sistem Basis Data berbantuan Komputer (Computer Assisted Instruction/ CAI).

\section{KAJIAN LITERATUR}

CAI (Computer Assisted Instruction) adalah salah satu model pembelajaran berbantuan komputer yang dapat menggunakan berbagai model pembelajaran, seperti: model tutorial, latihan dan praktik, simulasi, dan pendekatan pemecahan masalah untuk menyajikan topik, dan menguji pemahaman siswa. Program-program ini memungkinkan siswa mempelajari materi dengan langkah mereka sendiri.

Model pembelajaran berbantuan komputer terdiri atas beberapa jenis, antara lain:

1) Model Drill and Practice: merupakan suatu model dalam pembelajaran dengan jalan latihan dan praktik secara terus menerus. Model ini juga dapat menambah kecepatan, kesempurnaan dalam melakukan sesuatu serta dapat pula dipakai untuk mengulangi bahan yang disajikan.

2) Model Tutorial: merupakan bimbingan pembelajaran dalam bentuk pemberian bimbingan, bantuan, petunjuk, arahan dan motivasi agar peserta didik belajar secara efisien dan efektif. Pemberian bantuan berarti membantu peserta didik dalam mempelajari materi pelajaran. Model Tutorial merupakan program pembelajaran yang digunakan dalam 
proses pembelajaran dengan menggunakan software berupa program komputer yang berisi materi pelajaran.

Riset-riset mengenai sistem pembelajaran telah banyak menguji penggunaan model CAI. Widayanti menguji penggunaan CAI pada mata pelajaran Sistem Operasi Kelas X Sekolah Menengah Kejuruan di Indonesia. Penelitian tersebut menunjukkan respon siswa terhadap media pembelajaran sebesar 73,75\% termasuk dalam kategori baik dan hasil belajar siswa berada pada rata-rata 82,00 pada posttest (Isni, Setya, dan Chendra 2016).

Suleman, Hussain, Din, dan Iqbal (2017) menguji efek CAI pada pembelajaran Fisika siswa Sekolah Menengah Atas. Mereka menemukan bahwa pembelajaran berbasis CAI memiliki efek positif yang signifikan terhadap prestasi akademik dan retensi siswa dalam Fisika, dan merekomendasikan penggunaan teknik pembelajaran berbantuan komputer bagi guru sains.

Jasmy, Rahman, dan Ismail (2014) juga telah menguji efek CAI pada pembelajaran Fisika (Analisis Gerakan dan Vektor) untuk siswa Sekolah Menengah Atas. Hasil temuan mereka menunjukkan bahwa terdapat peningkatan motivasi belajar dan pemahaman konseptual siswa pada pembelajaran yang menggunakan media berupa perangkat lunak interaktif.

Pada penelitian ini dikembangkan model CAI berbasis kombinasi Tutorial dan Drill \& Practice sebagai model pembelajaran Sistem Basis Data. Model pembelajaran Sistem Basis Data berbasis CAI dikemas dalam bentuk cetak dan bentuk Aplikasi berbasis Web/E-learning, yang didalamnya berisi uraian materi dan link video pembelajaran secara online, sehingga memberikan peluang bagi mahasiswa untuk mengexplore sumbersumber belajar secara tak terbatas, di mana saja dan kapan saja. Dengan kombinasi model Tutorial dan Drill and Practice, model ini sesuai dengan karakteristik objek pembelajaran Sistem Basis Data yang menuntut konsep pembelajaran yang menekankan pemahaman konseptual pada awal pembelajaran, dan memerlukan latihan mendalam untuk mengekspos kasus-kasus yang tidak terstruktur.

\section{METODE PENELITIAN}

Penelitian yang diakukan menggunakan metode R \& D (Research and Development), karena memenuhi empat ciri utama yang diperkenalkan oleh Borg and Gall (Wibawa, 2014), yaitu melakukan studi awal untuk mencari informasi mengenai produk pembelajaran yang akan dikembangkan, mengembangkan produk berdasarkan hasil temuan penelitian, melakukan uji coba lapangan terhadap produk yang dikembangkan, dan merevisi produk berdasarkan hasil uji coba agar menjadi produk bermanfaat yang menjawab kebutuhan.

\section{Teknik Pengumpulan Data}

1) Observasi lapangan, dilakukan untuk mengetahui berbagai bahan pembelajaran yang telah digunakan di tempat penelitian selama ini.

2) Wawancara dan FGD, melibatkan pihak pemangku kepentingan, alumi, mahasiswa dan para pakar mengenai kondisi pembelajaran selama ini di tempat penelitian, tantangan serta kebutuhan. Wawancara bertujuan mendapatkan masukan mengenai model pembelajaran yang akan dikembangkan.

3) Angket, digunakan khususnya pada penelitian pendahuluan, untuk melihat persepsi alumni dan mahasiswa terhadap mata kuliah dan pembelajaran sistem basis data serta karakteristik mahasiswa. Angket juga digunakan untuk mendapatkan data mengenai model pembelajaran yang akan dikembangkan, serta digunakan untuk mengukur efektivitas penggunaan produk pembelajaran. 
4) Pretest dan posttest, untuk mengetahui efektifitas model sistem pembelajaran yang dikembangkan.

\section{Teknik Pengukuran Kualitas Produk}

Pengukuran kualitas produk dimaksudkan untuk mengetahui kualitas produk pembelajaran sistem basis data berbasis CAI dengan kombinasi model Tutorial dan model Drill and Practice berdasarkan aspek keefektifan. Efektivitas model diukur dengan menghitung persentase ketuntasan belajar mahasiswa. Presentase ketuntasan $(\mathrm{X})=$ (Jumlah mahasiswa yang tuntas/Jumlah mahasiswa) x 100\%. Selanjutnya, hasil persentase ketuntasan mahasiswa dikategorikan berdasarkan kriteria penilaian kecakapan akademik (Widoyoko, 2019).

Tabel 1 Kriteria Keefektifan Produk

\begin{tabular}{|c|c|c|}
\hline NO & $\begin{array}{c}\text { Rentang Persentase } \\
\text { Ketuntasan }\end{array}$ & Kriteria \\
\hline 1 & $\mathrm{X}>80$ & Sangat Baik \\
\hline 2 & $60<\mathrm{X} \leq 80$ & Baik \\
\hline 3 & $40<\mathrm{X} \leq 60$ & Cukup \\
\hline 4 & $20<\mathrm{X} \leq 40$ & Kurang \\
\hline 5 & $\mathrm{X} \leq 20$ & Sangat Kurang \\
\hline $\begin{array}{l}\text { dik } \\
\text { me }\end{array}$ & $\begin{array}{l}\text { Model pembela } \\
\text { bangkan dikatakan } \\
\text { nuhi kriteria minima }\end{array}$ & $\begin{array}{lr}\text { ran } & \text { yang } \\
\text { efektif } & \text { jika } \\
\text { aik. } & \end{array}$ \\
\hline
\end{tabular}

Efektivitas juga diukur dengan melihat signifikansi perolehan hasil pretest dan hasil posttest pada uji coba produk.

\section{Teknik Analisis Data}

Data yang berasal dari hasil wawancara atau Angket serta observasi, diolah secara kualitatif dengan menggunakan triangulasi, untuk selanjutnya diperoleh kesimpulan dari hasil pengolahan data. Rentang data hasil Angket menggunakan skala Likert (skala 5), yaitu; $5=$ sangat baik, $4=$ baik, $3=$ cukup, $2=$ kurang, $1=$ sangat kurang.

\section{HASIL DAN PEMBAHASAN}

\section{Model CAI yang Diusulkan}

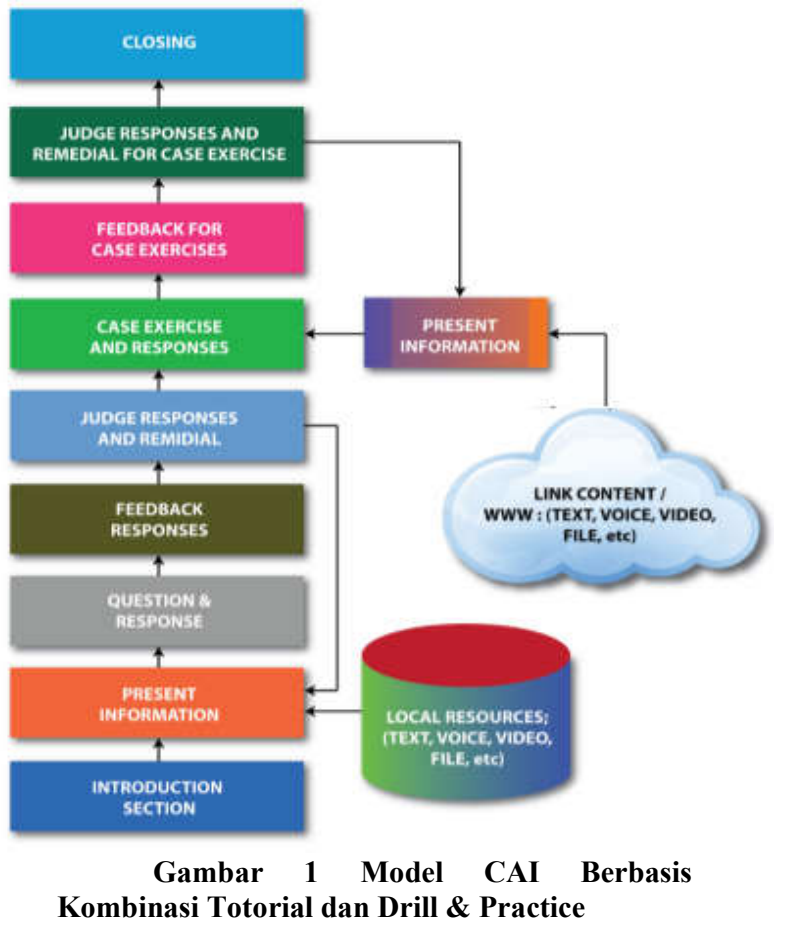

Model CAI pada gambar 1 berjalan pada platform berbasis Web atau terintegrasi pada aplikasi CMS (Content Management System) seperti e-Learning. Sistem digunakan untuk membantu siswa belajar secara mandiri kapan saja dan di mana saja, dan juga digunakan pada pembelajaran di kelas dengan pendampingan pengajar. Prosedur CAI berbasis kombinasi Tutorial dan Drill and Practice yang diusulkan terdiri atas 9 langkah, seperti berikut: 1) Introduction Section: Sistem CAI menampilkan petunjuk atau langkah-langkah pembelajaran yang harus ditempuh. 2) Present Information: Sistem CAI menyajikan materi yang bersumber dari lokal resources aplikasi sistem CAI yang dikemas dalam bentuk skrip tutorial. Informasi yang disajikan berupa informasi visual selain teks seperti gambar, grafik, foto dan image/vidio. 3) Question and Response: Sistem CAI menyajikan pertanyaan dan menilai sejauh mana kemampuan siswa mengingat dan memahami pelajaran yang disajikan. Tahapan ini merupakan tahap evaluasi 
yang menyatu dalam tahap penyajian materi. 4) Feedback Response: Sistem CAI memberikan umpan balik sebagai reaksi terhadap respon yang diberikan siswa. Fungsi umpan balik adalah untuk menginformasikan apakah respons yang diberikan siswa tepat atau tidak. Umpan balik berupa pesan-pesan dalam bentuk teks dan bentuk ilustrasi grafik. Jika respon yang diberikan siswa tepat, maka program memberikan penguatan bagi siswa. Namun jika respons siswa salah, program memberikan keterangan hukuman bahwa respons yang diberikannya salah. 5 Judge Response and Remedial: Sistem CAI menilai dan mengevaluasi jawaban/respon siswa agar feedback dapat diberikan kepada siswa. Penilaian berfungsi untuk mengevaluasi hasil belajar siswa dan membuat keputusan apakah proses belajar dapat dilanjutkan ke tahap berikutnya atau diulang. Pengulangan berbentuk penyajian kembali materi yang pernah dilihat siswa, yang bersumber dari local resources. 6) Case Exercise and Response: Sistem CAI menyajikan pertanyaan-pertanyaan dalam bentuk Studi Kasus Baru, namun masih relevan dengan materi-materi yang pernah dipelajari/dilihat siswa, serta menilai sejauh mana kemampuan siswa mengembangkan suatu materi tertentu yang telah disajikan. Sesi ini dapat dicapai oleh siswa jika seluruh materi utama pembelajaran telah dilalui dan dikuasai dengan sempurna. 7) Feedback for Case Exercise: Sistem CAI memberikan umpan balik sebagai reaksi terhadap respon yang diberikan siswa, seperti pada langkah keempat. 8) Judge Response and Remedial for Case Exercise: Sistem CAI menilai dan mengevaluasi jawaban/respon siswa agar feedback dapat diberikan kepada siswa. Penilaian berfungsi untuk mengevaluasi hasil latihan kasus dan membuat keputusan apakah proses belajar dapat dilanjutkan ke tahap berikutnya atau diulang. Pengulangan berbentuk penyajian materi pengayaan yang bersumber dari online resources / internet (www, unduh file, you tobe, etc) untuk memperkaya wawasan siswa sebelum melakukan latihan kasus kembali. Konsep ini dapat melatih siswa berfikir kritis dan mengembangkan wawasan atas materi pokok yang telah ditetapkan. 9) Closing: Sistem CAI menyajikan ringkasan informasi mengenai pelajaran berupa poin-poin utama sebuah paragraf tentang tujuan pembelajaran, serta memberikan rekomendasi untuk pembelajaran selanjutnya.

Langkah pertama hingga langkah ke lima adalah struktur logika dasar model CAI berbasis Tutorial, sedangkan langkah ke enam hingga langkah ke delapan merupakan inti dari model CAI berbasis Drill and Practice. Kedua model ini terintegrasi menghasilkan prosedur logik pembelajaran berupa menerapkan sistem Tutorial pada awal pembelajaran untuk memberikan pemahaman konseptual bagi siswa dan pada bagian akhir pembelajaran penyediaan latihan-latihan untuk mengembangkan kreativitas serta menguji kemampuan siswa.

\section{Efektivitas Model}

Ujicoba model dilakukan dengan menerapkan model CAI yag dikembangkan pada 29 orang mahasiswa semester dua Program Studi Sistem Informasi, Sekolah Tinggi Manajemen Informatika dan Komputer (STMIK) Banjarbaru Tahun 2020. Ujicoba dilakukan sebanyak 3 kali pertemuan, dimana pada setiap pertemuan pembelajaran diawali dengan memberikan pretest kepada mahasiswa dan diakhiri dengan posttest. Hasil ujicoba disajikan pada Tabel 2.

Pada Tabel 2 terlihat rerata nilai hasil belajar mahasiswa untuk pretest sebesar 43,69 (persentase ketuntasan sebesar $6,90 \%$ ), sedangkan rerata nilai posttest sebesar 75,21 (persentase ketuntasan sebesar 79,31\%). Hal ini 


\begin{tabular}{|c|c|c|c|c|}
\hline Res: & $\begin{array}{c}\text { Rerata } \\
\text { Pre- } \\
\text { test }\end{array}$ & Ketuntasan & $\begin{array}{l}\text { Rerata } \\
\text { Post-test }\end{array}$ & Ketuntasan \\
\hline 1 & 74 & Tuntas & 92 & Tuntas \\
\hline 2 & 70 & Tuntas & 88 & Tuntas \\
\hline 3 & 28 & Belum & 70 & Tuntas \\
\hline 4 & 43 & Belum & 73 & Tuntas \\
\hline 5 & 29 & Belum & 70 & Tuntas \\
\hline 6 & 48 & Belum & 90 & Tuntas \\
\hline 7 & 25 & Belum & 82 & Tuntas \\
\hline 8 & 25 & Belum & 55 & Belum \\
\hline 9 & 35 & Belum & 85 & Tuntas \\
\hline 10 & 49 & Belum & 80 & Tuntas \\
\hline 11 & 43 & Belum & 85 & Tuntas \\
\hline 12 & 51 & Belum & 86 & Tuntas \\
\hline 13 & 55 & Belum & 83 & Tuntas \\
\hline 14 & 49 & Belum & 76 & Tuntas \\
\hline 15 & 58 & Belum & 76 & Tuntas \\
\hline 16 & 14 & Belum & 29 & Tuntas \\
\hline 17 & 31 & Belum & 54 & Belum \\
\hline 18 & 49 & Belum & 78 & Tuntas \\
\hline 19 & 68 & Belum & 91 & Tuntas \\
\hline 20 & 26 & Belum & 61 & Belum \\
\hline 21 & 35 & Belum & 48 & Belum \\
\hline 22 & 58 & Belum & 86 & Tuntas \\
\hline 23 & 39 & Belum & 82 & Tuntas \\
\hline 24 & 59 & Belum & 84 & Tuntas \\
\hline 25 & 13 & Belum & 45 & Belum \\
\hline 26 & 66 & Belum & 91 & Tuntas \\
\hline 27 & 53 & Belum & 83 & Tuntas \\
\hline 27 & 53 & Belum & 83 & Tuntas \\
\hline 28 & 36 & Belum & 77 & Tuntas \\
\hline
\end{tabular}

Untuk menilai tingkat efektivitas model, data yang digunakan adalah nilai posttest dengan kriteria ketuntasan seperti yang disajikan pada Tabel 1, dan dengan klasifikasi nilai sebagai berikut:

$$
\begin{aligned}
& \mathrm{X}>\mathrm{Xi}+0,6 \text { Sbi : Efektif } \\
& \mathrm{X} \leq \mathrm{Xi}+0,6 \text { Sbi: Tidak Efektif }
\end{aligned}
$$

Tabel 3 menunjukkan sejumlah 24 dari 29 responden mencapai hasil yang efektif, sehingga tingkat keefektifan model pembelajaran Database berbasis CAI yang dikembangkan mencapai $82,76 \%(24 / 29 \mathrm{x}$ $100 \%)$.

Untuk mengetahui apakah terdapat peningkatan yang signifikan antara nilai

\begin{tabular}{|c|c|c|c|}
\hline Res: & Nilai & Kriteria & Keefektifitan \\
\hline 1 & 92 & Sangat Baik & Efektif \\
\hline 2 & 88 & Sangat Baik & Efektif \\
\hline 3 & 70 & Baik & Efektif \\
\hline 4 & 73 & Baik & Efektif \\
\hline 5 & 70 & Baik & Efektif \\
\hline 6 & 90 & Sangat Baik & Efektif \\
\hline 7 & 82 & Sangat Baik & Efektif \\
\hline 8 & 55 & Cukup & Tidak Efektif \\
\hline 9 & 85 & Sangat Baik & Efektif \\
\hline 10 & 80 & Baik & Efektif \\
\hline 11 & 85 & Sangat Baik & Efektif \\
\hline 12 & 86 & Sangat Baik & Efektif \\
\hline 13 & 83 & Sangat Baik & Efektif \\
\hline 14 & 76 & Baik & Efektif \\
\hline 15 & 76 & Baik & Efektif \\
\hline 16 & 29 & Kurang & Tidak Efektif \\
\hline 17 & 54 & Cukup & Tidak Efektif \\
\hline 18 & 78 & Baik & Efektif \\
\hline 19 & 91 & Sangat Baik & Efektif \\
\hline 20 & 61 & Baik & Efektif \\
\hline 21 & 48 & Cukup & Tidak Efektif \\
\hline 22 & 86 & Sangat Baik & Efektif \\
\hline 23 & 82 & Sangat Baik & Efektif \\
\hline 24 & 84 & Sangat Baik & Efektif \\
\hline 25 & 45 & Cukup & Tidak Efektif \\
\hline 26 & 91 & Sangat Baik & Efektif \\
\hline 27 & 83 & Sangat Baik & Efektif \\
\hline 28 & 77 & Baik & Efektif \\
\hline 29 & 81 & Sangat Baik & Efektif \\
\hline Rerat & 75,21 & Baik & Kompeten \\
\hline
\end{tabular}
pretest dan posttest, dilakukan uji signifikansi perbedaan rata-rata pretest dan posttest dengan menggunakan uji-t. Hasil uji-t menunjukkan perbedaan yang signifikan, dengan taraf signifikansi 0,05 . Diperoleh nilai t-hitung sama dengan 14,112 dengan signifikansi 0,000. Karena nilai t-hitung lebih kecil dari alpha 5\%, dapat disimpulkan bahwa terdapat perbedaan yang signifikan hasil belajar mahasiswa sebelum dan sesudah menerapkan strategi pembelajaran sistem 
basis data menggunakan CAI berbasis Tutorial dan Drill and Practice.

\section{Pembahasan Hasil Uji Model}

Efektivitas penerapan model pembelajaran menggunakan CAI berbasis Tutorial dan Drill and Practice secara simultan menghasilkan pencapaian standar kompetensi minimum yang ditetapkan dalam rancangan pembelajaran Sistem Basis Data pada Prodi Sistem Informasi STMIK Banjarbaru (sebesar 70). Seperti yang ditunjukkan pada hasil uji efektivitas model, nilai rerata post-test mencapai 75,21 , dengan $82,76 \%$ mahasiswa dinyatakan tuntas dalam pencapaian standar minimum kompetensi yang ditetapkan. Hal ini mengalami peningkatan yang cukup signifikan (mencapai 72,41\%) dari nilai rerata pretest yang hanya mencapai 43,69, dengan prosentase ketuntasan hanya mencapai $6,90 \%$. Hasil ini sejalan dengan temuan Suleman, Hussain, Din, dan Iqbal (2017) bahwa CAI memberikan efek yang signifikan terhadap prestasi siswa dalam proses pembelajaran.

\section{KESIMPULAN}

Penerapan model pembelajaran berbasis Computer Assisted Instruction (CAI) menggunakan kombinas model Tutorial dan Drill and Practice secara simultan dapat menghasilkan pencapaian standar kompetensi minimum yang ditetapkan dalam rancangan pembelajaran (sebesar 70). Seperti yang ditunjukkan pada hasil uji efektivitas produk, nilai rerata pos-ttest menjapai 75,21 , dengan $82,76 \%$ mahasiswa dinyatakan tuntas dalam pencapaian standar minimum kompetensi yang ditetapkan. Hal ini mengalami peningkatan yang cukup signifikan (mencapai $72,41 \%$ ) dari nilai rerata pre-test yang hanya mencapai 43,69 , dengan proseantase ketuntasan hanya mencapai $6,90 \%$. Hasil uji signifikasi antara post-test dan pre-test juga memperlihatkan peningkatan yang signifikan.
Oleh karena Model CAI yang diuji coba pada paper ini terintegrasi dalam sebuah desain instruksional, studi lebih lanjut diperlukan untuk mengkaji segmen mana yang memberikan kontribusi yang lebih signifikan dalam pencapaian hasil belajar Sistem Basis Data, model CAI atau model Desain Instruksional.

\section{REFERENSI}

Darmawan, D. 2011. Teknologi Pembelajaran (2nd ed.). Rosada Karya.

Isni, W., \& Setya, Chendra, W. 2016. Pengembangan Model Pembelajaran Computer Assisted Instruction ( CAI) Tipe Tutorial Dengan Aplikasi Lectora Inspire Pada Mata Pelajaran Sistem Operasi Kelas X SMK. It-Edu, 1(2), 65-69.

Jasmy, M., Rahman, A., Arif, M., Ismail, H., \& Nasir, M. 2014. Development and Evaluation of the Effectiveness of Computer-Assisted Physics Instruction. 7(13), 14-22.

Mario G, P., \& Oscar, D. 2000. Advanced Database Technology and Design (1st ed.). Artech House.

Ramez, E., \& Shamkant B, N. 2016. Fundamentals of Database systems. Seventh Edition (Seventh). Pearson Higher Education.

Simarmata, J., Limbong, T., Katolik, U., Thomas, S., Utara, S., Sriadhi, S., Medan, U. N., \& Tambunan, A. 2018. Learning Application of Multimedia-Based-Computer

Network Using Learning Application of MultimediaBasedComputer Network Using Computer Assisted Instruction Method. August, 8-12.

Suleman Q., Hussain, Din M. \& Iqbal K. 2017. Effects of Computer-Assisted Instruction (CAI) on Students' Academic Achievement in Physics at Secondary Level Effects of 
Computer-Assisted Instruction ( CAI ) on Students 'Academic Achievement in Physics at Secondary Level. Computer Engineering and Intelligent Systens, 8 No.7(October), 9-17

Wibawa, B., Mahdiyah, \& Afgani, J. 2014. Metode Penelitian Pendidikan. Universitas Terbuka.

Widoyoko, S. E. P. 2019. Evaluasi Program Pembelajaran (Panduan Praktis Bagi Pendididik Dan Calon Pendidik) (X). Pustaka Pelajar.

Yuelan, L., Yiwei, L., Yuyan, H., \& Yuefan, L. 2011. Study on teaching methods of database application courses. Procedia Engineering, 15, 5425-54 